\title{
Low Oxygen Affinity Hemoglobin Solution Increases Oxygenation of Partially Ischemic Tissues during Acute Anemia
}

\author{
Pedro Cabrales, PhD \\ Department of Bioengineering, University of California, San Diego, La Jolla, CA
}

\section{Abstract}

BACKGROUND-Maintenance of post-surgical tissue oxygenation depends on the ability of the specific tissue to recruit perfusion and oxygen $\left(\mathrm{O}_{2}\right)$ supply. However, when native $\mathrm{O}_{2}$ carrying capacity is lacking, fluids to improve $\mathrm{O}_{2}$ carrying capacity based in hemoglobin $(\mathrm{Hb})$ could prevent partially ischemic tissue hypoxia by increasing $\mathrm{O}_{2}$ release from the remaining red blood cells.

STUDY DESIGN—Responses to facilitated $\mathrm{O}_{2}$ transport after exchange transfusion with polymerized bovine $\mathrm{Hb}(\mathrm{PBH})$ were studied in a chronic partially ischemic tissue model, induced by large feeding arterioles ligation during hamster window chamber model implantation. PBH affects in microvascular perfusion and tissue oxygenation were studied after exchange transfusion of $40 \%$ of animal's blood volume. Experimental groups were defined by the concentration of PBH used, namely: PBH at $13 \mathrm{~g} / \mathrm{dl}$ [PBH13], $\mathrm{PBH}$ at $4 \mathrm{~g} / \mathrm{dl}$ in albumin solution to matching colloidal osmotic pressure (COP) [PBH4], and no PBH only albumin solution at matching COP [PBH0].

RESULTS—Restitution of $\mathrm{O}_{2}$ carrying capacity with PBH13 increased blood pressure and produced vasoconstriction compared to PBH4 and PBH0. On the other hand, PBH4 maintained blood pressure without significant vasoconstriction, increased tissue $\mathrm{pO}_{2}$, arteriolar $\mathrm{O}_{2}$ supply and extraction to the partially ischemic tissue compared to PBHO and PBH13.

CONCLUSIONS-Results suggest the existence of an optimal concentration of low $\mathrm{O}_{2}$ affinity acellular $\mathrm{Hb}$ to increase oxygenation of partially ischemic tissue during anemic conditions.

\section{Keywords}

Microcirculation; hemoglobin based oxygen carriers; post-surgical tissue; hemodilution; functional capillary density; exchange transfusion; hemoglobin oxygen affinity; tissue oxygen

\section{INTRODUCTION}

\begin{abstract}
Partial ischemia is defined as moderated restriction of blood supply to an organ or tissue. This ischemia induces moderated accumulation of metabolic products, and changes on inflammation and permeability, mostly because the oxygenation and energy supply are still provided by the high oxygen $\left(\mathrm{O}_{2}\right)$ caring capacity in the blood, and blood perfusion is reduced. Although, many partially ischemic conditions occur in conjunction with moderated changes
\end{abstract}

Correspondence address: Pedro Cabrales, Ph.D., Department of Bioengineering, University of California, San Diego, La Jolla, CA 92093 , Telephone: (858) 534-2315, pcabrales@ucsd.edu.

Disclosure Information: Nothing to disclose.

Publisher's Disclaimer: This is a PDF file of an unedited manuscript that has been accepted for publication. As a service to our customers we are providing this early version of the manuscript. The manuscript will undergo copyediting, typesetting, and review of the resulting proof before it is published in its final citable form. Please note that during the production process errors may be discovered which could affect the content, and all legal disclaimers that apply to the journal pertain. 
in blood $\mathrm{O}_{2}$ carrying capacity (surgery, bleeding, trauma, etc), impeding maintenance of homeostasis and cell function, and if untreated it will result in local tissue necrosis. ${ }^{1}$ During surgery, the reasons for ischemia are manifold. Soft tissue trauma, burn injuries, and prolonged immobilization can result in partially ischemia-related complications. Almost any surgical dissection implies direct vascular trauma, thus compromising microvascular perfusion. ${ }^{2}$ Reduction of the anatomical blood supply secondary to surgery results in areas of tissue with microhemodynamic disturbances, which are prone to ischemic complications and consequently may cause significant morbidity.

Maintenance of post-surgical tissue oxygenation during acute isovolemic anemia depends on physiologic adjustments occurring at both the systemic and the microcirculatory level. Undisturbed tissues compensate for the anemia by increasing perfusion and $\mathrm{O}_{2}$ extraction. However, the relative contribution of these mechanisms depends on the ability of the specific tissue to recruit each of them. The tolerance to partial ischemic tissue to acute isovolemic anemia will also depend on the level of $\mathrm{O}_{2}$ demand. The inspired $\mathrm{O}_{2}$ fraction could also influence the tolerance to anemia, but the contribution of $\mathrm{O}_{2}$ dissolved in the plasma is very limited, compared to lung free radical formation and subsequent tissue damage. ${ }^{3}$

Hemoglobin $(\mathrm{Hb})$ based $\mathrm{O}_{2}$ carriers (HBOCs) blood substitutes are being developed to overcome limitations inherent to blood transfusion. ${ }^{4}$ It has been amply demonstrated that unmodified $\mathrm{Hb}$ can not be used as HBOCs due to its nephrotoxicity, which is partially overcome by $\mathrm{Hb}$ polymerization. ${ }^{5}$ However, polymerized $\mathrm{Hb}$ remains vasoactive, an effect attributed to nitric oxide (NO) scavenging, extravasation and vasculature hyperoxygenation. ${ }^{6}$ Increase in blood pressure is the most frequent clinical manifestation of vasoconstriction and remains the main unwanted side effect. HBOCs have been formulated to reproduce $\mathrm{O}_{2}$ carrying capacity similar to blood. However, they tend increase $\mathrm{O}_{2}$ release from RBCs to tissues via the process of facilitated oxygen diffusion.

The objective of this study was to identify the role of circulating concentration of low $\mathrm{O}_{2}$ affinity $\mathrm{Hb}$ in oxygenation of partially ischemic tissue during anemic conditions. Partially ischemic tissue was induced by ligation of major feeding arterioles during hamster chamber window model preparation. The partially ischemic hamster chamber window model tissue had significant reduction in blood perfusion. Acute anemic conditions were induced by isovolemic hemodilution of $40 \%$ of the blood volume, decreasing systemic Hct from $49 \%$ to $29 \%$ (RBC $\mathrm{Hb}$ from $14.8 \mathrm{~g} / \mathrm{dl}$ to $9.7 \mathrm{~g} / \mathrm{dl}$ ). To achieve this objective, the window model was exchanged transfused with different concentrations of polymerized bovine $\mathrm{Hb}\left(\mathrm{PBH}\right.$, Oxyglobin ${ }^{\circledR}$, Biopure Corporation, Cambridge, MA; approved in the United States and European Union for veterinary use). $\mathrm{PBH}$ concentrations tested were 0,4 , and $13 \mathrm{~g}_{\mathrm{PBH}} / \mathrm{dl}$ at matching colloidal osmotic pressure (COP). COP was adjusted with human serum albumin diluted in normal saline.

\section{METHODS}

\section{Animal Preparation}

Investigations were performed in 55 - $65 \mathrm{~g}$ male Golden Syrian Hamsters (Charles River Laboratories, Boston, MA). The hamster window chamber model is widely used for microvascular studies in the unanesthetized state, and the complete surgical technique is described in detail elsewhere. ${ }^{7}{ }^{8}$ Partial ischemia was induced by ligation of major feeding arterioles during dorsal window implantation (Figure 1A). Arterial and venous catheters filled with a heparinized saline solution $(30 \mathrm{IU} / \mathrm{ml})$ were implanted in to the carotid and jugular vessels. Catheters were tunneled under the skin, exteriorized at the dorsal side of the neck, and securely attached to the window frame. Animal handling and care followed the NIH Guide for 
the Care and Use of Laboratory Animals. The experimental protocol was approved by the local animal care committee.

\section{Inclusion Criteria}

The microvasculature was examined 3 to 4 days after the window implantation surgery, and only animals passing an established systemic and microcirculatory inclusion criteria. Animals were suitable for the experiments if systemic parameters were within normal range, namely, heart rate $(\mathrm{HR})>340$ beat/min, mean arterial blood pressure (MAP) $>80 \mathrm{mmHg}$, systemic $\mathrm{Hct}>45 \%$, and arterial $\mathrm{O}_{2}$ partial pressure $\left(\mathrm{p}_{\mathrm{A}} \mathrm{O}_{2}\right)>50 \mathrm{mmHg}$; and microscopic examination of the tissue in the chamber observed under a x650 magnification did not reveal signs of low perfusion, inflammation, edema or bleeding. Hamsters are a fossorial species with a lower arterial $\mathrm{pO}_{2}$, however, their microvascular $\mathrm{pO}_{2}$ distribution in the chamber window model is similar to other rodents. ${ }^{9}$

\section{Acellular $\mathrm{Hb}$ solution}

Polymerized bovine $\mathrm{Hb}(\mathrm{PBH})$ commercially available as Oxyglobin ${ }$ (Oxyglobin ${ }$, Biopure Corporation, Cambridge, MA). $\mathrm{PBH}$ is produced by non specific polymerization with glutaraldehyde (mean molecular weight $200 \mathrm{kDa}$ ) in a modified Lactated Ringer's Solution. PBH (Oxyglobin $®)$ has a concentration of $13 \mathrm{~g}_{\mathrm{Hb}} / \mathrm{dl}$ (COP: $38 \mathrm{mmHg}$, viscosity: $1.9 \mathrm{cp}$ ). Additional PBH concentrations evaluated were 0 and $4 \mathrm{~g}_{\mathrm{Hb}} / \mathrm{dl}$. COP of all solution was balance using human serum albumin diluted in normal saline to $38 \mathrm{mmHg}$. $\mathrm{PBH}$ solution viscosities for 0 and $4 \mathrm{~g}_{\mathrm{Hb}} / \mathrm{dl}$ were $1.2 \mathrm{cp}$ and $1.3 \mathrm{cp}$, respectively.

\section{Acute Isovolemic Exchange Transfusion (Hemodilution) Protocol}

Prior to the exchange transfusion, animals were randomly divided into three experimental groups. ${ }^{10}$ Briefly, the volume of the exchange-transfusion was calculated as $40 \%$ of the blood volume, estimated as $7 \%$ of body weight. The acute anemic state was induced by exchanging $40 \%$ of the animal blood volume with the test solution. Simultaneously, blood was withdrawn from the carotid artery catheter, and test solution was infused using the from the jugular vein catheter at the same rate, Figure 2.

\section{Experimental groups}

The experimental groups were labeled $\mathrm{PBHO}, \boldsymbol{P B H 4}$ and $\boldsymbol{P B H} 13$ based in the concentration of PBH used. Group 1) PBH13, exchange transfusion with stock solution of $\mathrm{PBH}$ (Oxyglobin®); Group 2) PBH4, exchange transfusion with $\mathrm{PBH}$ diluted to $4 \mathrm{~g}_{\mathrm{Hb}} / \mathrm{dl}$; Group 3) $\boldsymbol{P B H 0}$, exchange transfusion without $\mathrm{PBH}$.

\section{Systemic Parameters}

MAP and HR were recorded continuously (MP 150, Biopac System; Santa Barbara, CA). Hct was measured from centrifuged arterial blood samples taken in heparinized capillary tubes. $\mathrm{Hb}$ content was determined spectrophotometrically (B-Hemoglobin, Hemocue, Stockholm, Sweden).

\section{Blood Chemistry and Biophysical Properties}

Arterial blood was collected in heparinized glass capillaries (50 $\mu \mathrm{l})$ and immediately analyzed for $\mathrm{pO}_{2}, \mathrm{pCO}_{2}$, base excess (BE) and $\mathrm{pH}$ (Blood Chemistry Analyzer 248, Bayer, Norwood, MA). Viscosity was measured in a DV-II plus (Brookfield, Middleboro, MA). Plasma COP was measured using a 4420 Colloid Osmometer (Wescor, Logan, UT). Blood samples were withdrawn at the end of the experiment for subsequent analysis of viscosity and COP. 


\section{Microvascular Experimental Setup}

The unanesthetized animal was placed in a restraining tube with a longitudinal slit from which the window chamber protruded, then fixed to the microscopic stage for transillumination with the intravital microscope (BX51WI, Olympus, New Hyde Park, NY). Animals were given 20 min to adjust to the tube environment before any measurement. Tissue image was projected onto a charge-coupled device camera (COHU 4815) connected to a videocassette recorder and viewed on a monitor. Measurements were carried out using a 40X (LUMPFL-WIR, numerical aperture 0.8 , Olympus) water immersion objective. Systemic and microcirculation data was taken after a stabilization period of 20 min post hemodilution.

\section{Functional Capillary Density (FCD)}

Functional capillaries, defined as those capillary segments that have RBC transit of at least a single $\mathrm{RBC}$ in a $45 \mathrm{~s}$ period in 10 successive microscopic fields were assessed, totaling a region of $0.46 \mathrm{~mm}^{2}$. The relative change in FCD from baseline levels after each intervention is indicative of the extent of capillary perfusion. ${ }^{11}$

\section{Microhemodynamics}

Microvascular parameter were characterized for large feeding and small arcading arterioles (range $45-74 \mu \mathrm{m}$ ) and small collecting and venules (range 46-76 $\mu \mathrm{m}$ ). Arteriolar and venular blood flow velocities were measured on-line by using the photodiode cross-correlation method (Photo Diode/Velocity Tracker Model 102B, Vista Electronics, San Diego, CA). The measured centerline velocity was corrected according to vessel size to obtain the mean RBC velocity (V) ${ }^{12}$. A video image-shearing method was used to measure vessel diameter (D) ${ }^{13}$. Blood flow (Q) was calculated from the measured values as $\mathrm{Q}=\pi \times \mathrm{V}(\mathrm{D} / 2)^{2}$. This calculation assumes a parabolic velocity profile and has been found to be applicable to tubes of $15-80 \mu \mathrm{m}$ internal diameters and for Hcts in the range of $6-60 \% .^{12}$

\section{Microvascular $\mathrm{pO}_{2}$ distribution}

High resolution non-invasive microvascular $\mathrm{pO}_{2}$ measurements were made using phosphorescence quenching microscopy $(\mathrm{PQM}) .{ }^{14,15} \mathrm{PQM}$ is based on the $\mathrm{O}_{2}$-dependent quenching of phosphorescence emitted by albumin-bound metalloporphyrin complex after pulsed light excitation. PQM is independent of the dye concentration within the tissue and is well suited for detecting hypoxia because its decay time is inversely proportional to the $\mathrm{pO}_{2}$ level, causing the method to be more precise at low $\mathrm{pO}_{2}$ 's. This technique is used to measure both intravascular and extravascular $\mathrm{pO}_{2}$ since the albumin-dye complex continuously extravasates from the circulation into the interstitial tissue. ${ }^{14}, 15$ Tissue $\mathrm{pO}_{2}$ was measured in tissue regions in between functional capillaries. PQM allows for precise localization of the $\mathrm{pO}_{2}$ measurements, without subjecting the tissue to injury. These measurements provide a detailed understanding of microvascular $\mathrm{O}_{2}$ distribution and indicate whether $\mathrm{O}_{2}$ is delivered to the interstitial areas.

\section{Oxygen supply and extraction}

The microvascular methodology used in our studies allows a detailed analysis of $\mathrm{O}_{2}$ delivery to the tissue. Calculations are made using equation $1, \mathrm{O}_{2}$ supply $\left(\mathrm{DO}_{2}\right)$ and $2, \mathrm{O}_{2}$ extraction $\left(\mathrm{VO}_{2}\right) \cdot{ }^{11}$

$$
D O_{2}=\left[\left(R B C_{H b} \times \gamma \times S_{A}\right)+\left(\text { Plasma }_{H b} \times \gamma \times \breve{S}_{A}\right)\right] \times Q
$$




$$
V O_{2}=\left[\left(R B C_{H b} \times \gamma \times S_{A-V}\right)+\left(\text { Plasma }_{H b} \times \gamma \times \check{S}_{A-V}\right)\right] \times Q
$$

where $R B C_{H b}$ is the $\mathrm{Hb}$ from RBCs equal to Total $\mathrm{Hb}$ - plasma $\mathrm{Hb}\left[\mathrm{g}_{\mathrm{Hb}} / \mathrm{dl}_{\text {blood }}\right.$, Plasma ${ }_{H b}$ is the acellular $\mathrm{Hb}\left[\mathrm{g}_{\mathrm{Hb}} / \mathrm{dl}_{\text {blood }}\right], \gamma$ is the $\mathrm{O}_{2}$ carrying capacity of saturated $\mathrm{Hb}\left[1.34 \mathrm{mlO} \mathrm{O}_{2} / \mathrm{g}_{\mathrm{Hb}}\right]$, $\mathrm{S}_{\mathrm{A}} \%$ is the arteriolar $\mathrm{RBC} \mathrm{O}_{2}$ saturation and $\breve{\mathrm{S}}_{\mathrm{A}} \%$ is the arteriolar $\mathrm{PBH} \mathrm{O}_{2}$ saturation, $\mathrm{A}-\mathrm{V}$ indicates the arteriolar/venular differences, and $\mathrm{Q}$ is the microvascular flow. Fresh hamster RBCs at $\mathrm{pH} 7.4$ and $37.6{ }^{\circ} \mathrm{C}$ had a $\mathrm{P} 50(50 \%$ of the $\mathrm{Hb}$ is saturated with oxygen) of $32 \mathrm{mmHg}$ and Hill number of 2.9 measured using Hemox Analyzer (TCS Corp., PA). PBH is only $72 \%$ saturated at $150 \mathrm{mmHg}$, therefore P50 is $54 \mathrm{mmHg}$ and Hill number of 1.2. ${ }^{16}$

\section{Data Analysis}

Tabular results are presented as mean \pm standard deviation. The box-whisker plot separates the data into quartiles, top of the box defining the $75^{\text {th }}$ percentile, the line within the box giving the median, and the bottom of the box showing the $25^{\text {th }}$ percentile. Upper whisker defines the $95^{\text {th }}$ percentile, and lower whisker the $5^{\text {th }}$ percentile. Data within each group were analyzed using analysis of variance for repeated measurements (ANOVA, Kruskal-Wallis test). When appropriate, post hoc analyses were performed with the Dunns multiple comparison test. Microhemodynamic data are presented as absolute values and ratios relative to baseline values. A ratio of 1.0 signifies no change from baseline while lower and higher ratios are indicative of changes proportionally lower and higher than baseline (i.e., 1.5 would mean a 50\% increase from the baseline level). The same vessels and capillary fields were followed so that direct comparisons to their baseline levels could be performed, allowing for more robust statistics for small sample populations. All statistics were calculated using GraphPad Prism 4.01 (GraphPad Software, Inc., San Diego, CA). Changes were considered statistically significant if $\mathrm{P}<0.05$.

\section{RESULTS}

Eighteen animals were entered the exchange transfusion protocol. Six animals were assigned to each experimental group. Groups were statistically similar $(\mathrm{P}>0.30)$ in systemic and microcirculation parameters at baseline. Systemic and microhemodynamic data for baseline was obtained combining data from all experimental groups. Microhemodynamics of partial ischemic dorsal hamster windows at baseline compared, non ischemic dorsal hamster windows are shown in Figure 1B. Data for non ischemic dorsal hamster windows was obtained from six additional animals.

\section{Systemic Parameters}

Exchange transfusion reduced Hct and Hb. Blood chemistry at baseline and exchange transfusion is presented in Table 1. Hct for all experimental groups was similar. Total $\mathrm{Hb}$ was increased proportional to the concentration of $\mathrm{PBH}$ used during the exchange transfusion. Hct after exchange transfusion remained stable over time until the end of the experiment for all experimental groups.

MAP was statistically decreased from baseline for $\boldsymbol{P B H O}$. $P$ BH13 statistically increased MAP from baseline and compared to $\boldsymbol{P B H O}$ and $\boldsymbol{P B H 4}$. HR was not statistically affected by the exchange transfusion. Systemic arterial blood gases are presented in Table 1. Arterial $\mathrm{pO}_{2}$ was statistically increased from baseline after exchange transfusion for all groups. Arterial $\mathrm{pCO}_{2}$ decreased from baseline after exchange transfusion. Arterial $\mathrm{pO}_{2}, \mathrm{pCO}_{2}$ and $\mathrm{pH}$ were not different among experimental groups. Blood $\mathrm{BE}$ was decreased after exchange transfusion for 
all experimental groups compared to baseline, however no difference among experimental groups was observed.

\section{Microhemodynamics}

The changes in diameter and blood flow after exchange transfusion relative to baseline are presented in Figure 3. Absolute values are given in the Figure 2 legend. Arteriolar diameter of the partially ischemic tissue was statistically constricted for exchange transfusion with

$\boldsymbol{P B H 1 3}$ compared to $\boldsymbol{P B H} 4$ and $\boldsymbol{P B H O}$. Venular diameters of the partially ischemic tissue were not different after exchange transfusion. Arteriolar and venular blood flows were not different after exchange transfusion among groups.

\section{Functional Capillary Density}

FCD of the partially ischemic tissue after exchange transfusion with different PBH concentration are presented in Figure 4. FCD was reduced after exchange transfusion for all groups. FCD after exchange transfusion with $\boldsymbol{P B H 1 3}$ was statistically decreased compared to PBHO.

\section{Microvascular Oxygen Tensions}

Intravascular and tissue $\mathrm{pO}_{2} \mathrm{~s}$ of the partially ischemic tissue after exchange transfusion are shown in Figure 5. $\boldsymbol{P B H 4}$ yielded high intravascular (arteriolar and venular) $\mathrm{pO}_{2} \mathrm{~s}$ when compared to $\boldsymbol{P B H O}$ and $\boldsymbol{P B H 1 3}$. Additionally, exchange transfusion with $\boldsymbol{P B H 4}$ produced higher interstitial tissue $\mathrm{pO}_{2}$ than $\boldsymbol{P B H O}$ and $\boldsymbol{P B H 1 3}$.

\section{Oxygen Supply and Extraction}

Figure 6 shows analysis of systemic and microvascular $\mathrm{O}_{2}$ supply and extraction. Systemic $\mathrm{O}_{2}$ supply after exchange transfusion was not different among groups. Arteriolar $\mathrm{O}_{2}$ supply to the partially ischemic tissue was higher for $\boldsymbol{P B H} 4$ compare to $\boldsymbol{P B H O}$, and $\boldsymbol{P B H 1 3 .}$ Microcirculation $\mathrm{O}_{2}$ extraction was statistically reduced for $\boldsymbol{P B H O}$ when compared to $\boldsymbol{P B H} \boldsymbol{4}$ and $\boldsymbol{P B H}$ 13. Microcirculation $\mathrm{O}_{2}$ extraction ratio $\left(\mathrm{O}_{2}\right.$ supplied/ $\mathrm{O}_{2}$ extracted $)$ was lower for $\boldsymbol{P B H 4}$ when compared to $\boldsymbol{P B H O}$ and $\boldsymbol{P B H 1 3}$. Consequentially venular $\mathrm{O}_{2}$ reserve was statistically increased for $\boldsymbol{P B H} 4$ compared to $\boldsymbol{P B H O}$ and $\boldsymbol{P B H 1 3 .}$

\section{DISCUSSION}

The principal finding of the study is that low $\mathrm{O} 2$ affinity $\mathrm{Hb}$ solutions can be used to increase microvascular $\mathrm{O}_{2}$ transport to partially ischemic tissues during anemic conditions. Moderate concentrations of PBH (PBH4) appear to be more effective than stock concentration of PBH $(\boldsymbol{P B H} 13)$ to enhance oxygenation of the partially ischemic tissue. The importance of increasing plasma $\mathrm{O}_{2}$ carrying capacity to prevent anoxia of partially ischemic tissue during acute anemic conditions is shown by the higher interstitial tissue $\mathrm{pO}_{2}$ and calculated microvascular $\mathrm{O}_{2}$ extraction compared to without acellular $\mathrm{Hb}$ in plasma $(\boldsymbol{P B H O})$. Colloidal osmotic properties were not a factor during the study, because solution COP was matched before infusion, and verified by the lack of differences in Hct between groups. Since there were no differences in native $\mathrm{O}_{2}$ transport capacity (Hct), the differences found between groups are mostly due to changes in plasma $\mathrm{O}_{2}$ carrying capacity by the $\mathrm{PBH}$.

Partially ischemic tissue induced by major arterial ligation, are noticeably sensitive to changes in native $\mathrm{O}_{2}$ carrying capacity. Previous experiments performed in the hamster window model, without the arteriole ligation, produced changes in hemodynamic parameters to compensate for the reduction in $\mathrm{O}_{2}$ carrying capacity. ${ }^{14}$ Normal tissues maintained $\mathrm{O}_{2}$ delivery during moderate hemodilution by increasing local perfusion, facilitated by the decrease in blood 
viscosity and the systemic increases in and cardiac output. ${ }^{17}$ A decreased of $40 \%$ of the Hct in hamster window model without arterial ligation does not produce significant changes in interstitial tissue $\mathrm{pO}_{2} .14$ However, when partial ischemia is induced, by feeding arterial ligation, a $40 \%$ decrease in $\mathrm{Hct}$ significantly compromised interstitial tissue $\mathrm{pO}_{2}$, as presented by the current study. Exchange transfusion with different concentrations of PBH produced MAP and vascular tone responses proportional to plasma $\mathrm{PBH}$ concentration. PBH plasma concentration did not increase central $\mathrm{O}_{2}$ arterial supply, while it significantly affected arteriolar $\mathrm{O}_{2}$ supply to the partially ischemic tissue. However, the arteriolar $\mathrm{O}_{2}$ supply to the partially ischemic tissue was not proportional to the PBH plasma concentration, as only the moderate concentrations of $\mathrm{PBH}$ sustaining perfusion and took advantage of the increase in $\mathrm{O}_{2}$ carrying capacity. This result suggests the potential of moderate amounts of acellular low $\mathrm{O}_{2}$ affinity $\mathrm{HBOC}$ to ensure oxygenation of partially ischemic tissues.

The study presents a significant increase in partially ischemic tissue $\mathrm{O}_{2}$ supply when a moderate amount of PBH $(1.4 \mathrm{~g} / \mathrm{dl})$ was present in the anemic blood, while $89 \%$ of the $\mathrm{O}_{2}$ supplied was supplied by the RBCs and only $11 \%$ by the PBH. Without PBH in plasma, RBCs in the anemic blood arrived to the partially ischemic tissue with only $60 \%$ of the $\mathrm{O}_{2}$ presented in the blood when $1.4 \mathrm{~g} / \mathrm{dl}$ of PBH is present in the plasma. The presence of $3.7 \mathrm{~g} / \mathrm{dl}$ of PBH in plasma did not increase the $\mathrm{O}_{2}$ provided by the $\mathrm{RBC}$ to the partially ischemic tissue, however it presented similar $\mathrm{O}_{2}$ supplied that moderate concentration $\mathrm{PBH}$ by increasing the amount of $\mathrm{O}_{2}$ provided by the plasma $\mathrm{Hb}$. The low $\mathrm{O}_{2}$ affinity acellular $\mathrm{HBOC}$ brings more $\mathrm{O}_{2}$ into the partially ischemic area by increasing the fraction of $\mathrm{O}_{2}$ supplied by the RBCs and enhances $\mathrm{O}_{2}$ offload increasing arteriolar-venular $\mathrm{O}_{2}$ extraction and tissue $\mathrm{pO}_{2}$. These results show that moderated supplementation of plasma $\mathrm{O}_{2}$ carrying capacity is more effective than large increases, since a fraction of the $\mathrm{O}_{2}$ is preserved, to be released at the microcirculation, sustaining precapillary $\mathrm{O}_{2}$ released without triggering vascular $\mathrm{O}_{2}$ regulatory mechanisms. After a large reduction in the native $\mathrm{O}_{2}$ carrying capacity, maintenance of perfusion and $\mathrm{O}_{2}$ supply are advantageous. If only a plasma expander is used in optimal conditions only perfusion is sustained. When using an HBOC, perfusion and oxygenation can be affected by the simple strategy of HBOC dose titration as shown in the current study.

A possible mechanism for our demonstrated improvement in oxygenation with the low circulating acellular $\mathrm{Hb}$ concentration was the $\mathrm{O}_{2}$ supply to the partially ischemic tissue created by the low $\mathrm{O}_{2}$ affinity $\mathrm{Hb}$. While the MAP was sustained for all groups that received $\mathrm{PBH}$, only animals exchanged transfused with $13 \mathrm{~g} / \mathrm{dl}$ of PBH showed vasoconstriction. The higher perfusion pressure as a consequence of the higher MAP alone can not explain higher arteriolar $\mathrm{pO}_{2} \mathrm{~s}$, however combined with $\mathrm{Hb}$-bound $\mathrm{O}_{2}$ diffusion (facilitated diffusion), $\mathrm{HBOC}$ can offload $\mathrm{O}_{2}$ more efficiently in arteriolar-sized vessels than blood, because they overcome transport barriers associated with increased distance for $\mathrm{O}_{2}$ diffusion and low plasma $\mathrm{O}_{2}$ solubility. Moderated increases in plasma $\mathrm{O}_{2}$ carrying capacity with $\mathrm{PBH}$ provided better and prolonged maintenance of homeostasis when compared to stock concentration of $\mathrm{PBH}$ $(\boldsymbol{P B H} 13)$ or non PBH $(\boldsymbol{P B H O})$. Although PBH is broad mix of different molecular sizes, it appears that at low concentration the vasoconstrictive properties of the smaller Hb polymers are compensated by the facilitated $\mathrm{O}_{2}$ diffusion and the improved perfusions pressure. Therefore, the circulatory effects of $\mathrm{PBH}$ after exchange transfusion appear to represent a balance of positive (e.g., increased $\mathrm{O}_{2}$ carrying capacity and perfusion pressure) and negative (e.g. vasoconstriction) stimuli. In this context a moderate vasoactivity may have the beneficial effect of increasing perfusion pressure without compromising microvascular function and FCD.

PBH is a non specific glutaraldehyde polymerized $\mathrm{Hb}$, with low $\mathrm{O}_{2}$ affinity ( $\mathrm{P} 50$ of $54 \mathrm{mmHg}$ ), drastically reduced cooperativity and a broad distribution of molecular weights which significantly facilitates $\mathrm{O}_{2}$ offloading. ${ }^{18}$ To some extent low $\mathrm{O}_{2}$ affinity and reduced 
cooperativity has been interpreted as negative properties to replace or reinstate blood $\mathrm{O}_{2}$ carrying capacity. Although, during partial ischemic conditions a small acellular $\mathrm{Hb}$ diffuse fast and augment $\mathrm{O}_{2}$ transport by carrying $\mathrm{Hb}$-bound $\mathrm{O}_{2}$ to the partially ischemic tissue. In this condition PBH has a larger Biot number as a consequence of its reduced $\mathrm{O}_{2}$ affinity and $\mathrm{O}_{2}$ dissociation kinetics. The $\mathrm{O}_{2}$ delivery in the present of $\mathrm{HBOC}$ becomes a specific problem for each $\mathrm{Hb}$ preparation, depending on $\mathrm{O}_{2}$ affinity, molecular size, and amount infused.

Nevertheless, the optimal point to use a HBOC should (target) be defined by the $\mathrm{O}_{2}$ metabolic needs.

This study demonstrated that the administration of a low concentration of acellular HBOC with low $\mathrm{O}_{2}$ affinity, prevents hypoxic areas at plasma concentration of $1.4 \mathrm{~g}_{\mathrm{PBH}} / \mathrm{dl}$, and it appears that higher doses are not necessary because vasoconstriction induced by a larger dose counteracts the benefits in $\mathrm{O}_{2}$ transport. In recent studies, the toxicities of $\mathrm{Hb}$ solutions has been linked to oxidative stress, vasoconstriction and inflammation. $5,19,20$ Oxidative stress can be induced by $\mathrm{Hb}$ autooxidation and leads to the formation of reactive oxygen species. ${ }^{20}$, 21 There are many published experimental studies where the objective was to substitute the native $\mathrm{O}_{2}$ carrying capacity with HBOCs, without understanding the different nature of the materials. ${ }^{22}$ Over-expectation has been a major limiting factor in the development and approval of effective HBOC blood substitutes. Future investigations would be directed to potential side effects of this product with regard to partially ischemic tissue oxygenation.

In conclusion, anemic conditions drastically affect oxygenation of partially ischemic tissue, which can progress from hypoxia to more severe necrotizing form, if untreated. The arterial ligation produced tissue microcirculation disturbances, and as a consequence, decreased tissue oxygenation. At this point, specific therapy must be directed towards microcirculation perfusion and tissue oxygenation, as their preservation will prevent further progression. In essence, treatment of experimental partially ischemic tissue after exchange transfusion with $\mathrm{HBOC}$ like low $\mathrm{O}_{2}$ affinity acellular $\mathrm{Hb}$ can preserve microcirculation and improve tissue oxygenation, compared to hemodilution alone. These results were obtained at a specific anemic state, and it is likely that the relationship between central arterial supply and the ischemic tissue arteriolar $\mathrm{O}_{2}$ supply, microcirculation $\mathrm{O}_{2}$ extraction and tissue $\mathrm{pO}_{2}$ will change for different anemic conditions. A decrease of $40 \%$ of the native $\mathrm{O}_{2}$ carrying capacity, in the current partially ischemic model drastically affects its tissue $\mathrm{pO}_{2}$ in the absence of $\mathrm{PBH}$, while a plasma concentration of $1.4 \mathrm{~g} \mathrm{gBH}_{\mathrm{PB}} / \mathrm{dl}$ increased tissue $\mathrm{pO} 2$ and arteriolar supply, without vasoconstriction or hypertension. These effects were negated at plasma concentrations of 3.5 $\mathrm{g}_{\mathrm{PBH}} / \mathrm{dl}$, which produced an increase in MAP, peripheral vascular resistance and diminishing $\mathrm{O}_{2}$ transport benefits of $\mathrm{PBH}$, relative to those observed at lower concentrations. In summary, the results suggest the existence of an optimal concentration of low $\mathrm{O}_{2}$ affinity $\mathrm{Hb}$ to increase oxygenation of partially ischemic tissue during anemic conditions.

\section{Acknowledgments}

The authors thank Froilan P Barra and Cynthia Walser for the surgical preparation of the animals.

This work was supported by Bioengineering Research Partnership grant R24-HL64395, Program project P01 HL071064 and grants R01-HL62354, R01-HL62318 and R01-HL76182.

\section{References}

1. Sarani B, Strong M, Pascual J, Schwab CW. Necrotizing fasciitis: current concepts and review of the literature. J Am Coll Surg 2009;208:279-288. [PubMed: 19228540]

2. Nicholls TP, Shoemaker WC, Wo CC, et al. Survival, hemodynamics, and tissue oxygenation after head trauma. J Am Coll Surg 2006;202:120-130. [PubMed: 16377505] 
3. Freeman BA, Crapo JD. Hyperoxia increases oxygen radical production in rat lungs and lung mitochondria. J Biol Chem 1981;256:10986-10992. [PubMed: 7287745]

4. Winslow RM. Blood substitutes. Curr Opin Hematol 2002;9:146-151. [PubMed: 11844999]

5. Alayash AI. Oxygen therapeutics: Can we tame haemoglobin? Nature Reviews Drug Discovery 2004;3:152-159.

6. Winslow RM. Oxygen transport agents: a new approach to red blood cell alternatives. TATM 2004;5:498-504.

7. Colantuoni A, Bertuglia S, Intaglietta M. Quantitation of rhythmic diameter changes in arterial microcirculation. Am J Physiol 1984;246:H508-H517. [PubMed: 6720909]

8. Endrich B, Asaishi K, Götz A, Messmer K. Technical report: A new chamber technique for microvascular studies in unanaesthetized hamsters. Res Exp Med 1980;177:125-134.

9. Cabrales P, Tsai AG, Frangos JA, Intaglietta M. Role of endothelial nitric oxide in microvascular oxygen delivery and consumption. Free Radic Biol Med 2005;39:1229-1237. [PubMed: 16214038]

10. Altman DG, Bland JM. Statistics notes: How to randomise. BMJ 1999;319:703-704. [PubMed: 10480833]

11. Cabrales P, Tsai AG, Intaglietta M. Microvascular pressure and functional capillary density in extreme hemodilution with low and high plasma viscosity expanders. Am J Physiol 2004;287:H363-H373.

12. Lipowsky HH, Zweifach BW. Application of the "two-slit" photometric technique to the measurement of microvascular volumetric flow rates. Microvasc Res 1978;15:93-101. [PubMed: 634160]

13. Intaglietta M, Tompkins WR. Microvascular measurements by video image shearing and splitting. Microvasc Res 1973;5:309-312. [PubMed: 4709728]

14. Tsai AG, Friesenecker B, McCarthy M, et al. Plasma viscosity regulates capillary perfusion during extreme hemodilution in hamster skin fold model. Am J Physiol 1998;275:H2170-H2180. [PubMed: 9843817]

15. Kerger $\mathrm{H}$, Groth $\mathrm{G}$, Kalenka A, et al. $\mathrm{pO}_{2}$ measurements by phosphorescence quenching: characteristics and applications of an automated system. Microvasc Res 2003;65:32-38. [PubMed: 12535869]

16. Cabrales P, Tsai AG, Intaglietta M. Increased tissue PO2 and decreased $\mathrm{O} 2$ delivery and consumption after 80\% exchange transfusion with polymerized hemoglobin. Am J Physiol 2004;287:H2825-2833.

17. Cabrales $P$, Tsai AG. Plasma viscosity regulates systemic and microvascular perfusion during acute extreme anemic conditions. Am J Physiol Heart Circ Physiol 2006;291:H2445-2452. [PubMed: 16731641]

18. Tsai AG, Vandegriff KD, Intaglietta M, Winslow RM. Targeted $\mathrm{O}_{2}$ delivery by low-P50 hemoglobin: a new basis for $\mathrm{O}_{2}$ therapeutics. Am J Physiol Heart Circ Physiol 2003;285:H1411-H1419. [PubMed: 12805024]

19. D'Agnillo F, Alayash AI. Redox cycling of diaspirin crosslinked hemoglobin induces G2/M arrest and apoptosis in cultured endothelial cells. Blood 2001;98:3315-3323. [PubMed: 11719369]

20. Goldman DW, Breyer RJ 3rd, Yeh D, et al. Acellular hemoglobin-mediated oxidative stress toward endothelium: a role for ferryl iron. Am J Physiol 1998;275:H1046-1053. [PubMed: 9724312]

21. Giulivi C, Cadenas E. Heme protein radicals: formation, fate, and biological consequences. Free Radic Biol Med 1998;24:269-279. [PubMed: 9433902]

22. Fitzpatrick CM, Savage SA, Kerby JD, et al. Resuscitation with a blood substitute causes vasoconstriction without nitric oxide scavenging in a model of arterial hemorrhage. J Am Coll Surg 2004;199:693-701. [PubMed: 15501108] 

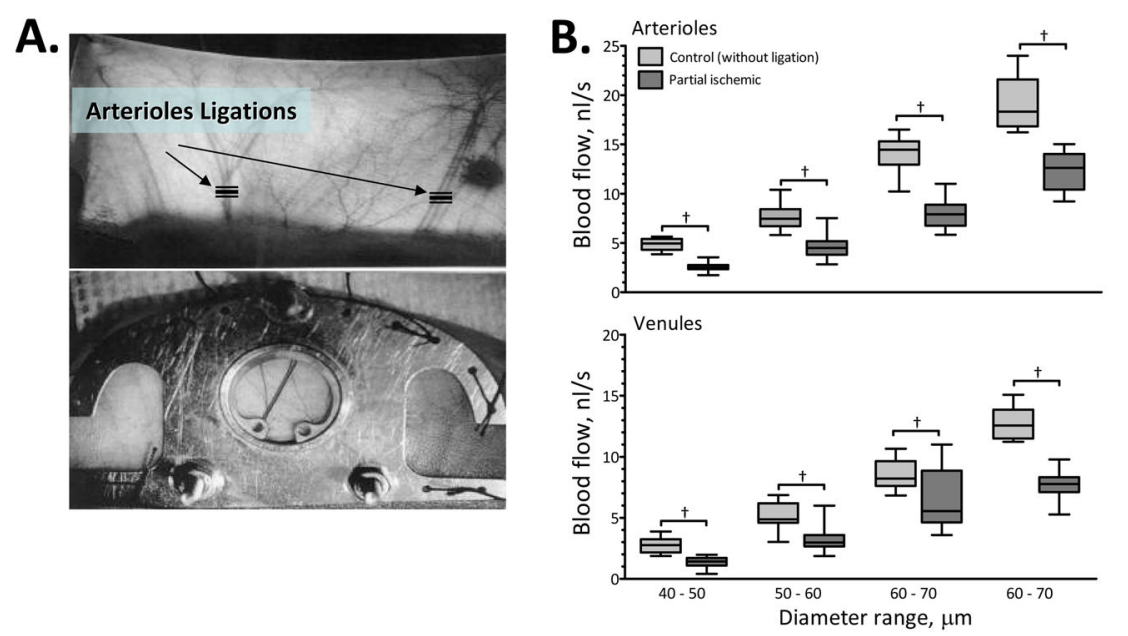

Figure 1.

(A) Partially ischemic hamster window chamber. Window implantation surgery includes ligation of large feeding arterioles. Ligations are marked with triple line. (B)

Microhemodynamic changes induced by feeding arterioles ligation. Significant decrease in blood flow all microvessel diameters were measured between conventional hamster window (red, control, without ligation) and partially ischemic hamster window (blue, partially ischemic). $\dagger, p<0.05$. Functional capillary density was higher in partially ischemic windows $\left(122 \pm 11 \mathrm{~cm}^{-1}\right)$ compared to control windows $\left(111 \pm 10 \mathrm{~cm}^{-1}\right), \mathrm{p}<0.10$. Intravascular and tissue $\mathrm{O}_{2}$ tensions are affected by arterioles ligation compared to non-ligated preparation. Arteriolar, venular and tissue $\mathrm{pO}_{2}$ for partially ischemic window are $33.5 \pm 3.3,16.4 \pm 2.8$ and $11.8 \pm 2.0 \mathrm{mmHg}$, respectively. Non-ischemic hamster window $\mathrm{pO}_{2}$ was statistically higher $(\mathrm{p}<0.05)$ for arteriolar, venular and tissue $\mathrm{pO}_{2}, 46.2 \pm 4.8,27.0 \pm 3.6$ and $20.9 \pm 2.9 \mathrm{mmHg}$, respectively. 


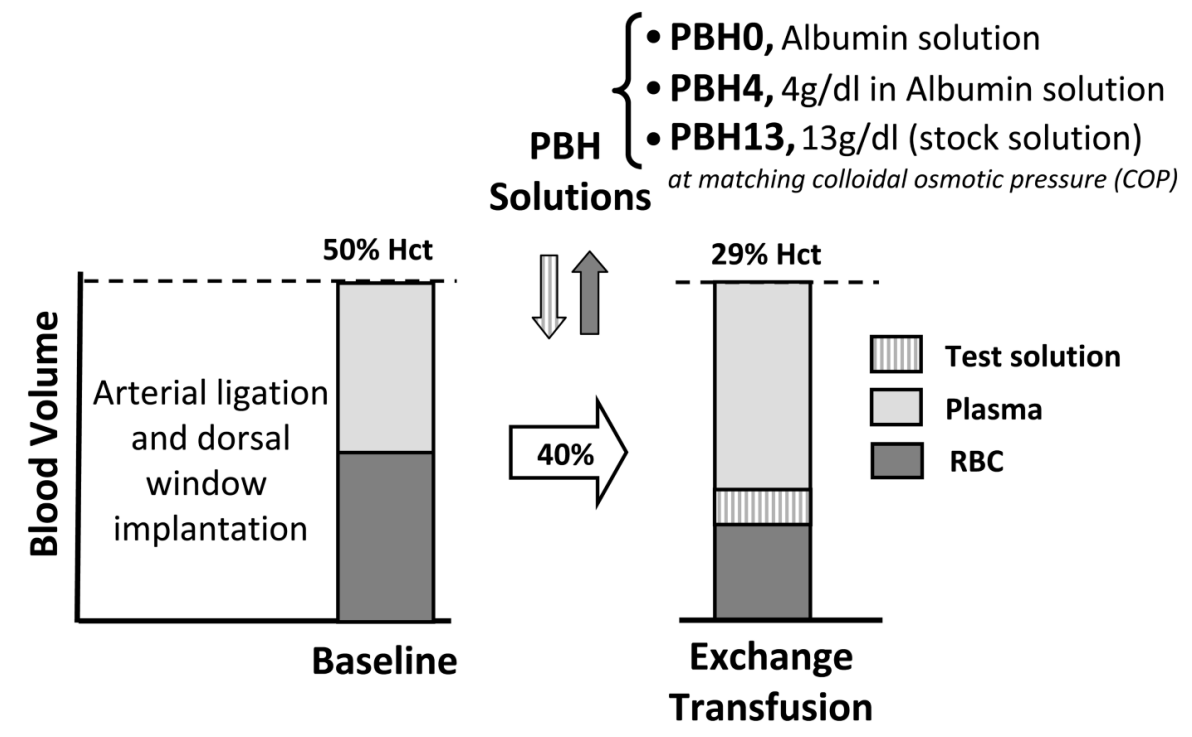

Figure 2.

Hemodilution protocol. Hemodilution was attained by means of isovolemic blood exchangetransfusion protocol in which red blood cell (RBC) volume (red bar) is continuously decreased and plasma volume is increased (open bar) while total blood volume remains constant (dashed line). The volume of the exchange-transfusion was calculated as $40 \%$ of blood volume, estimated as $7 \%$ of body weight. The acute anemic state was induced by exchange transfusion with polymerized bovine $\mathrm{Hb}(\mathrm{PBH}, \mathrm{Oxyglobin} ®$, Biopure Corporation, Cambridge, MA; approved in the United States and European Union for veterinary use). PBH concentrations evaluated were 0,4 , and $13 \mathrm{~g}_{\mathrm{PBH}} / \mathrm{dl}$ at matching colloidal osmotic pressure (COP). COP was adjusted with human serum albumin diluted in normal saline. Experimental groups were defined by the concentration of PBH used, namely: $\mathrm{PBH}$ at 13g/dl (PBH13), PBH at $4 \mathrm{~g} / \mathrm{dl}$ in albumin solution to matching colloidal osmotic pressure (COP) (PBH4), and no $\mathrm{PBH}$ only albumin solution at matching COP (PBH0). 


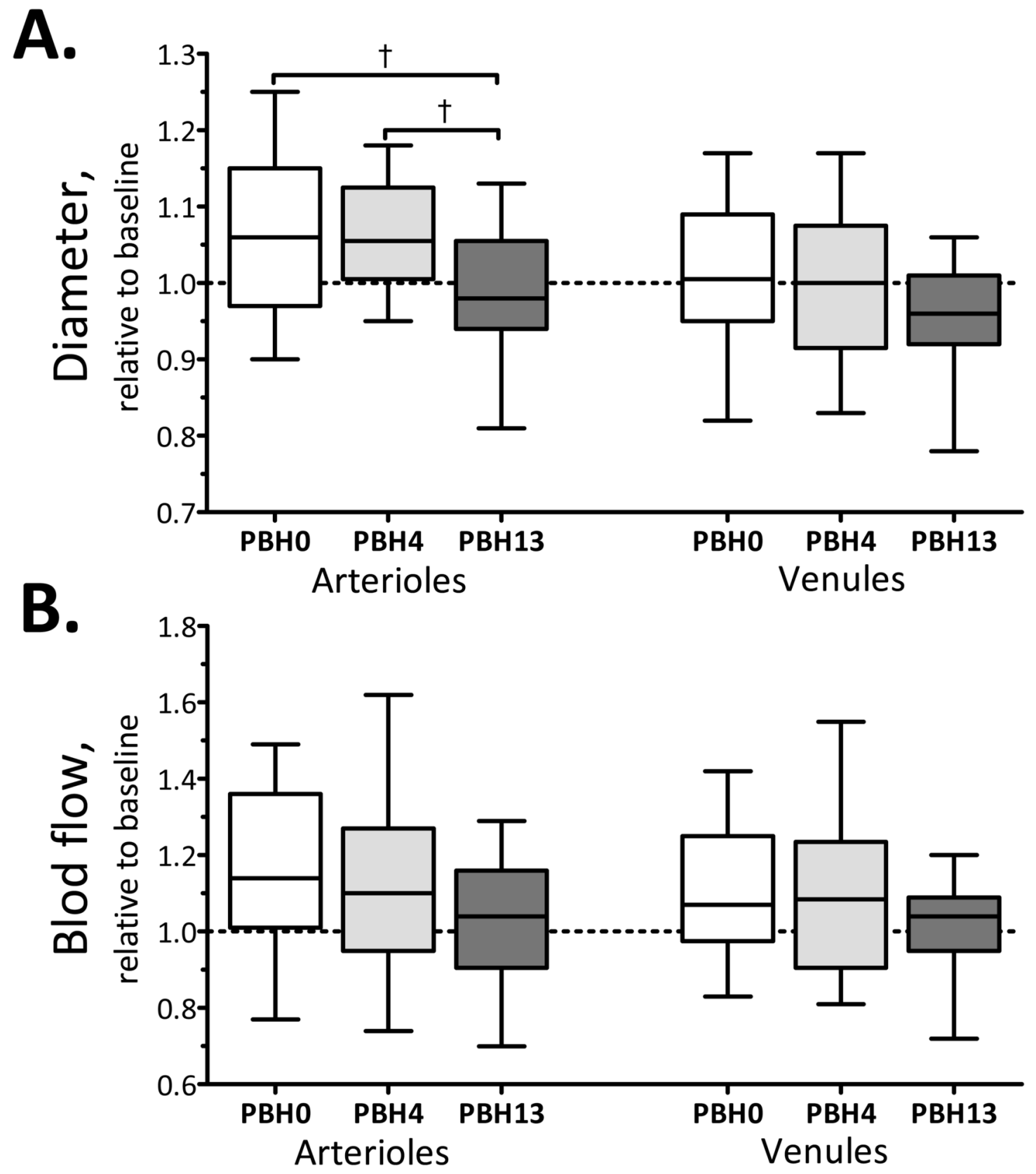

Figure 3.

Relative changes to baseline in arteriolar and venular hemodynamics. $\dagger, \mathrm{p}<0.05$. Baseline diameters $(\mu \mathrm{m}$, mean $\pm \mathrm{SD}$ ) for each animal group were as follows: PBH0 (arterioles (A): 66.9 $\pm 12.8, \mathrm{n}=22$; venules (V): $65.4 \pm 14.2, \mathrm{n}=32$ ); PBH4 (A: $65.4 \pm 14.5, \mathrm{n}=30 ; \mathrm{V}: 64.5 \pm 14.2$, $\mathrm{n}=32$ ); PBH13 (A: 63.2 $\pm 13.5, \mathrm{n}=26, \mathrm{~V}: 64.1 \pm 15.2, \mathrm{n}=31) . \mathrm{n}=$ number of vessels studied. Calculated baseline blood flows $(\mathrm{nl} / \mathrm{s}$, mean $\pm \mathrm{SD})$ for each animal group were as follows: PBH0 (arterioles $(\mathrm{A}): 7.1 \pm 3.1, \mathrm{n}=22$; venules $(\mathrm{V}): 4.5 \pm 2.2, \mathrm{n}=32$ ); PBH4 (A: $6.7 \pm 3.4$, $\mathrm{n}=30 ; \mathrm{V}: 4.7 \pm 2.5, \mathrm{n}=32)$; $\boldsymbol{P B H 1 3}(\mathrm{A}: 7.2 \pm 2.8, \mathrm{n}=26, \mathrm{~V}: 4.7 \pm 1.9, \mathrm{n}=31)$. 


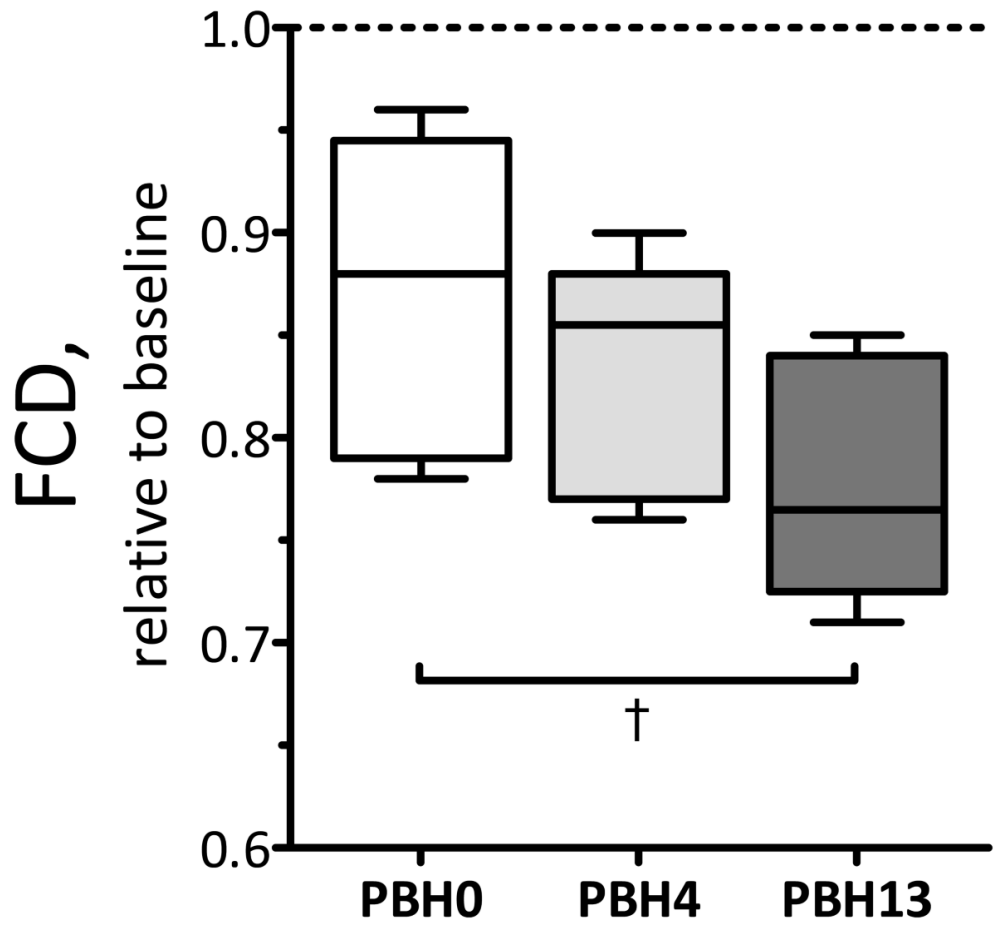

Figure 4.

Capillary perfusion during hemodilution. $\uparrow, \mathrm{p}<0.05$. FCD $(\mathrm{cm}-1)$ at baseline was as follows: PBH0 (124 \pm 11$)$; PBH4 (119 \pm 9); PBH13 (A: $120 \pm 12)$. 


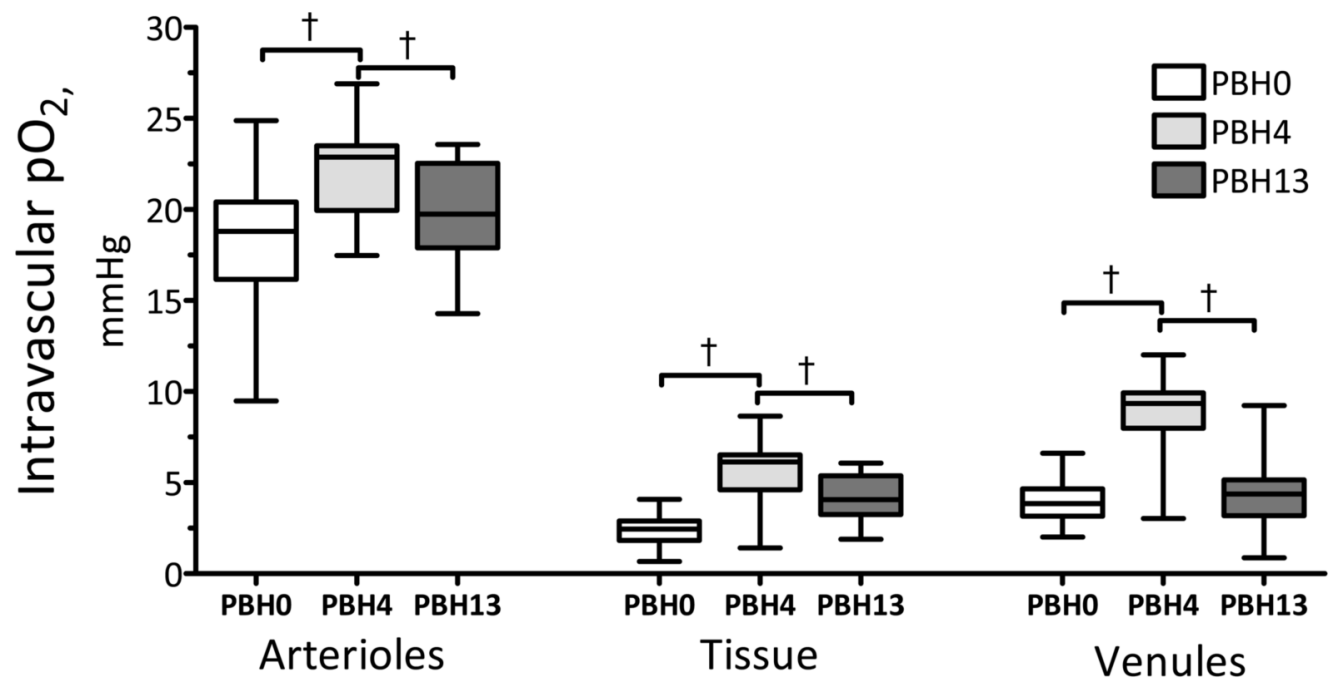

Figure 5.

Intravascular and tissue $\mathrm{pO}_{2}$ after exchange transfusion. $\dagger, \mathrm{p}<0.05$. Exchange transfusion with $\mathrm{PBH} 4$ produced higher intravascular (arteriolar and venular) $\mathrm{pO}_{2}$ s compared to exchange transfusion with $\mathrm{PBH} 0$ and $\mathrm{PBH} 13$, respectively. Interstitial tissue $\mathrm{pO}_{2}$ was also higher for exchange transfusion with $\mathrm{PBH} 4$ compared to exchange transfusion with $\mathrm{PBH} 0$ and $\mathrm{PBH} 13$. 


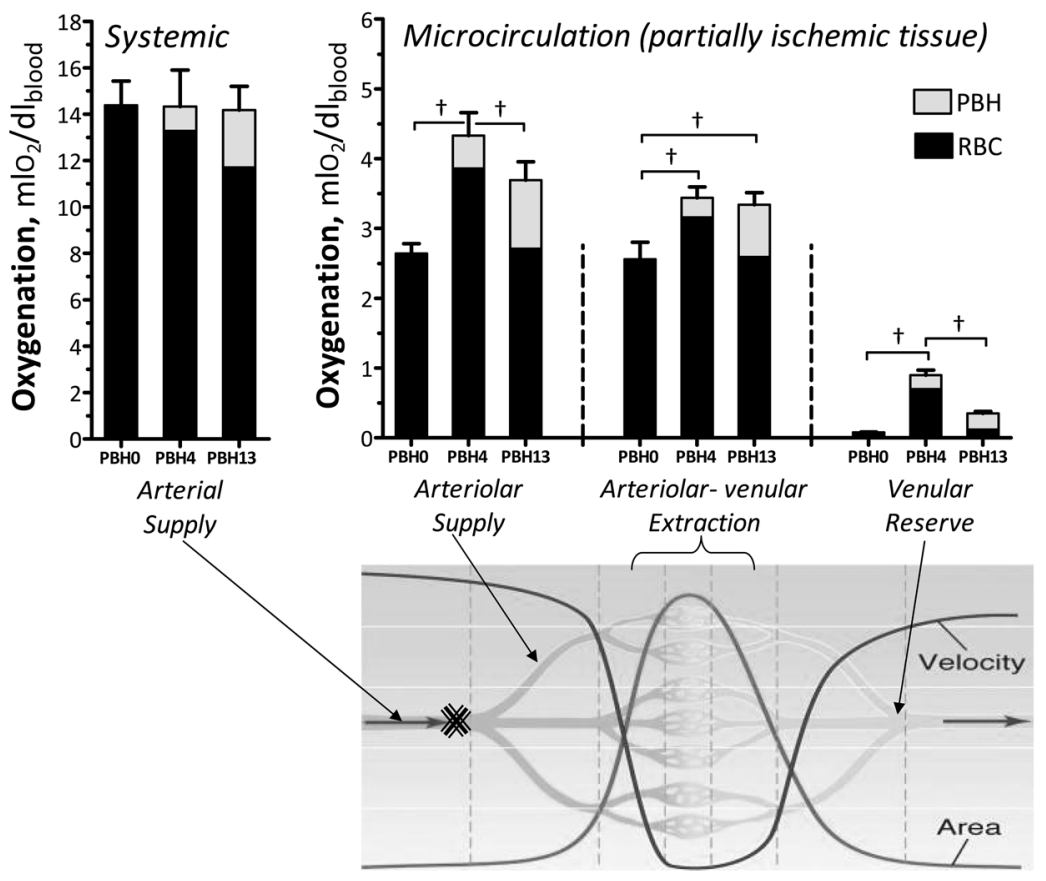

Figure 6.

Microvascular oxygen delivery and extraction. Oxygen transport by red blood cells (RBCs) and plasma $\mathrm{Hb} . \dagger, \mathrm{p}<0.05$. Systemic $\mathrm{O}_{2}$ supply after exchange transfusion was not different among groups. Arteriolar $\mathrm{O}_{2}$ supply to the partially ischemic tissue was higher for exchange transfusion with $\mathrm{PBH} 4$ compare to exchange transfusion with $\mathrm{PBH} 0$, and $\mathrm{PBH} 13$, respectively. Microcirculation $\mathrm{O}_{2}$ extraction was statistically reduced for exchange transfusion with $\mathrm{PBH} 0$ when compared to exchange transfusion with $\mathrm{PBH} 4$ and $\mathrm{PBH} 13$, respectively.

Microcirculation $\mathrm{O}_{2}$ extraction ratio $\left(\mathrm{O}_{2}\right.$ supplied $/ \mathrm{O}_{2}$ extracted) was lower for exchange transfusion with PBH4 when compared to exchange transfusion with PBH0 and PBH13, respectively. 
Table 1

Blood Gas Parameters

\begin{tabular}{|l|l|l|l|l|}
\hline & & \multicolumn{3}{|l|}{ Exchange transfusion, PBH solution } \\
\hline & Baseline & PBH0 & PBH4 & PBH13 \\
\hline $\mathrm{n}$ & 24 & 6 & 6 & 6 \\
\hline $\mathrm{Hct}, \%$ & $48.8 \pm 0.9$ & $28.8 \pm 0.8^{*}$ & $29.1 \pm 0.7^{*}$ & $29.2 \pm 0.7^{*}$ \\
\hline Total Hb, g/dL & $14.7 \pm 0.5$ & $9.4 \pm 0.4^{*+\neq}$ & $10.7 \pm 0.5^{* \neq}$ & $13.2 \pm 0.5^{* \dagger}$ \\
\hline Plasma Hb, g/dL & & & $1.4 \pm 0.3$ & $3.7 \pm 0.4$ \\
\hline $\mathrm{MAP}, \mathrm{mmHg}$ & $112 \pm 7$ & $92 \pm 7^{*+*}$ & $110 \pm 8^{* *}$ & $126 \pm 10^{* \dagger}$ \\
\hline $\mathrm{HR}, \mathrm{bpm}$ & $431 \pm 27$ & $452 \pm 36$ & $433 \pm 34$ & $409 \pm 30$ \\
\hline $\mathrm{P}_{\mathrm{a}} \mathrm{O}_{2}, \mathrm{mmHG}$ & $57.9 \pm 6.2$ & $72.7 \pm 8.9^{*}$ & $68.7 \pm 6.8^{*}$ & $74.7 \pm 8.1^{*}$ \\
\hline $\mathrm{P}_{\mathrm{a}} \mathrm{CO}_{2}, \mathrm{mmHg}$ & $54.0 \pm 5.2$ & $48.6 \pm 6.5$ & $50.2 \pm 6.0$ & $44.8 \pm 6.4$ \\
\hline $\mathrm{PH}_{\mathrm{a}}$ & $7.343 \pm 0.021$ & $7.337 \pm 0.020$ & $7.337 \pm 0.019$ & $7.353 \pm 0.026$ \\
\hline $\mathrm{BE}_{\mathrm{a}}, \mathrm{mmol}$ & $3.2 \pm 1.4$ & $0.8 \pm 1.6$ & $0.9 \pm 1.2$ & $0.2 \pm 1.8^{*}$ \\
\hline
\end{tabular}

Values are means \pm SD. Baseline includes all the animals.

$\mathrm{p}<0.05$ compared to baseline.

${ }^{\dagger} \mathrm{p}<0.05$ compared to $\mathrm{PBH}$.

${ }_{\mathrm{p}}{ }_{\mathrm{p}}<0.05$ compared to $\mathrm{PBH} 13$.

Hct, systemic hematocrit; Hb, hemoglobin content of blood; MAP, mean arterial blood pressure; HR, Heart rate; PaO2, arterial partial O2 pressure; $\mathrm{PaCO} 2$, arterial partial pressure of $\mathrm{CO} 2$; $\mathrm{BEa}$, arterial base excess. 